\title{
Delineating Prior Austenite Grain Boundaries in Carbon Steels
}

\author{
Samuel J. Lawrence \\ Lehigh University,Whitaker Laboratories, Bethlehem, PA 18016
}

Original austenite grain sizes are often required to determine steel microstructural characteristics for steel research and processing. This parameter has an effect on steel mechanical properties. Methods of delineating original austenite grains are oxidation of grain boundaries. McQuaid-Ehn testing and chemical reagent etchant attack, specifically with picric acid based etchants.There are disadvantages with oxidation and Mcquaid-Ehn methods in that they require long furnace holding times, which may result in austenite grain growth, and the results may misrepresent or misreport prior austenite grain (PAG) size. The chemical reagent etching technique has proven to be a more superior method because of its speed and reliability in determining PAG size.During the past fifty years metallurgists and metallographers have been involved in the development of etchants and procedures to delineate PAG boundaries in steels. [1] In 1938, J. R. Vilella [2] recommended the use of a picral-HCl based combination to etch PAG boundaries in tempered martensitic steel. The next significant step in the refinement of the etching technique was in 1947 when J. W. Cohen, A. Helich and M. Jacobson [3] noted that picric acid and a surfactant (wetting agent) in water selectively etched PAG boundaries in temper-embrittled NiCr steels. Bechet and Beaujard followed this with saturated aqueous picric acid $+1 \%$ Teepol $^{\mathrm{TM}}$ in 1955 [4]. G. A Dreyer, D. A Austin and W. D. Smith [5] reported that the surfactant sodium tridecylbenzene sulfonate $\left(\right.$ NansaSS60 ${ }^{\mathrm{TM}}$ ) was the best wetting agent as an additive to saturated aqueous picric acid for etching of PAG boundaries in 1964. R. A. Grange reported good etching results in steels that had been quenched then tempered for 16 hours at $510^{\circ} \mathrm{C}$ [6] and M.W. Lui and I. Lemay [7] noted that when etching for PAG boundaries, specific orientation of the specimen influenced etching response.

These seven investigations have provided basic guidelines for developing modern techniques for delineating PAG. There are others that have adapted and refined the procedures for specific steel compositions and heat treatments. PAG boundaries can be successfully delineated in a variety of steels with different microstructures by careful control of the etchant and specific etching procedures. Generally a picric acid solution appears to be the best base etchant, however variations or modification of general attack etchants, Marshalls reagent for example, can be used successfully with many specific steel types and microstructures. Variations of base etchant procedure and other modifications result in austenite grain boundary etching in a wide variety of steel chemistries, structures and heat treatments: quench and tempered martensite, bainites, ferritic bainites and ferrite-pearlite microstructures. Usually the higher the carbon, phosphorus, and niobium levels the better the etching response.

\section{References}

1. Kilpatrick, J. R. “Austenite Grain Boundary Etching Of High-Strength, Low Alloy Steels", Bethlehem Steel Corporation, August 1987, unpublished.

2. J. R. Vilella., "Metallographic Technique for Steel”, Trans. ASM, pg.38, (1938)

3. J.W. Cohen, A. Hurlich and M Jacobson, " A Metallographic Etchant to Reveal Temper Brittleness in Steel", Trans. ASM 39, pp. 109-136, (1947).

4. S. Bechet, and L. Beaujard, "Rev. Met." 52, 830-836, (1955).

5. G. A. Dreyer, D. A. Austin and W. D. Smith, "New Etchant Brings Out Grain Boundaries in Martensitc Steels" Metal Progress, 86, p.116, (1964).

6. R .A. Grange, “The Rapid Heat Treatment Of Steel”, Met. Trans 2, pp. 65-78, (1971).

7. M. W. Lui, and I. Lemay, "Etching of Prior Austenite Grain Boundaries in AISI 4140 Steel", Metallography, 4, pp.443-450, (1971). 